\title{
Is academic psychiatry for sale?
}

\author{
DAVID HEALY / MICHAEL E. THASE
}

Edited and introduced by Mary Cannon, Kwame McKenzie and Andrew Sims.

\section{INTRODUCTION}

The influence of the pharmaceutical industry on academic medicine is pervasive. $\mathrm{Al}-$ most $90 \%$ of authors published in the Journal of the American Medical Association have received research funding from, or acted as a consultant for, a drug company. Rising to this challenge, editors of medical journals have agreed strict rules on reporting sponsorship and conflicts of interest. Academic psychiatry is not exempt from the influence of industry. The relationship between drug companies and academic psychiatry is currently very close. But is this a problem? On the one hand, links with the pharmaceutical industry may be considered to compromise the independence of researchers and possibly discredit their published work. On the other hand the relationship may be seen as productive and mutually beneficial - particularly in an era of limited funds for research. These issues are discussed in this month's debate by Dr David Healy, Director of the North Wales Psychiatric Service, who is a well-known commentator on the pharmaceutical industry, and Dr Michael Thase, Professor of Psychiatry at the University of Pittsburgh School of Medicine and the author of a meta-analysis on the effectiveness of venlafaxine published in this Journal in 2001.

\section{FOR}

For the media it must be like shooting goldfish in a bowl. Go along to an international meeting, wait for psychiatrists coming out of the exhibition halls laden with pens, mugs, kites and CDs, in a relaxed frame of mind having had their massage done or their portrait painted, and ask: Does this not influence you? Our answer invariably is: No. How could this have much effect on us - we follow the evidence.

Exchanges like this are predicated on a failure on the part of clinicians to distinguish between sales and marketing. Sales is the subdivision of marketing responsible for producing all those things that fail to influence clinicians, from advertising in journals or on pens and mugs to 'directto-consumer' television slots. The sales department swings into action close to the launch of a drug. But the marketing department starts once a compound has been discovered. Marketing decides whether a new drug will be an antidepressant rather than an anxiolytic or a treatment for premature ejaculation. Marketing determines which journals with which lead authors clinical trials will appear in. Marketing recruits academics, including geneticists, neuroimaging specialists and social psychiatrists, to consultancy and speaker panels, and makes friends for the company. The marketing department supports educational events by putting on symposia, sponsoring speakers and bringing psychiatrists to international meetings. The work of the marketing departments is to create 'evidence' and establish consensus.

In the past year major journals have expressed concern at the ghostwriting of and conflicting interests surrounding pharmacotherapeutic studies, especially in psychiatry (Carpenter, 2002; Torrey, 2002). Some will see this as a set of minor criticisms of excesses in an otherwise smoothly functioning set of relations between academia and industry. Others clearly see emerging evidence of some unsuspected dimensions to a very successful industrial process.

The origins of this industrial process lie in the 1950s, when patients' access to new drugs was constrained within a system initially devised for addicts - prescription-only medicines. A gain in safety was the hopedfor trade-off from this curtailment of liberties - physicians would know what data were missing and what studies were needed to make a proper assessment of the risks and benefits of treatments, and they would force companies to supply the data and the studies. The system appeared to work when, following the thalidomide crisis a few years later, academics succeeded in setting the eye of a randomised controlled trial needle in front of the industrial camel (Healy, 2002).

It was not anticipated, however, that restricted to selling their compounds for disease entities and to physicians, companies would sell diseases and devote vast resources to educating physicians - roughly $£ 10000$ per annum per physician. Few could have expected in the 1960 s that companies would be able to market evidence of treatment effects from a minority of studies, as in the case of the selective serotonin reuptake inhibitors, as evidence of treatment efficacy, or that such evidence would be sufficient to lead to blockbuster status for these drugs.

The ability of companies to confound the expectations of those who would constrain them lies in a restructuring largely effected in the 1970s. This restructuring led to a separation between sales and marketing. It led to the establishment of contract research organisations, which replaced universities as the organisers of clinical trials. It led to medical writing agencies who now write the first and, often, all drafts of key review or clinical trial articles. This is a process to which senior academics increasingly make ornamental rather substantive contributions.

From these new arrangements stems the evidence clinicians seem to think keeps them safe on the academic high ground. However, between the collection of data in clinical trials and its presentation to clinicians there are a number of key interventions. First, companies regard trial data as proprietary. Clinicians only ever get presented with subsets of the data. Second, this selection of data gets called science and appears in the most prestigious journals and under the apparent authorship of 
leading figures in the field. It certainly has the appearances of science, but it is a cuckoo's egg in the nest of science.

For data to be scientific they must in principle be available for scrutiny. Ideally they should be generated in the process of answering scientific questions. Neither of these conditions is fulfilled by these business exercises. If there were any suspicions of significant discrepancies between the published and the collected data, one would expect an independent academic establishment to object. At the very least, one might expect published evidence of major discrepancies to be greeted with the disengagement of academic psychiatrists from company platforms. In fact, the most senior figures in academia are likely to be found endorsing the product.

Claiming that the data are proprietary might be acceptable if companies restricted their marketing to the time-honoured sales strategies of clinician freebies and celebrity endorsements. But one might have expected an independent academic establishment to force companies to abide by the rules of science, if 'science' is used as a marketing strategy. Academia should surely at least be able to emulate successful consumer organisations in other marketplaces in pointing to mismatches between evidence and hype - this at least was clearly the expectation of politicians, regulators and the public in the 1960s.

Unlike the pens and mugs, clinicians do not have the option of taking or leaving these products of company marketing departments. The fact that these infomercials' appear in all the best journals has consequences. The fact that these data selections become embodied in algorithms and protocols constructed by panels of academics has consequences, even though the interests of these academics, when scrutinised, are revealing. Clinicians are as dependent on their academics in this new marketplace as the public is on their clinicians.

At present, journal editors seem to be the fall guys who, equipped with the shovels of conflict of interest statements and the brooms of authorship declarations, are expected to clean out the Augean stables of an increasingly compromised academic literature, when what is needed is a breach in the dam of academic silence and a flood of refusals to accept that publications that involve data that are not publicly available should be called scientific. A failure to take a stand will leave us repeatedly cuckolded by every issue of our major journals.

David Healy North Wales Department of Psychological Medicine, Hergest Unit, Bangor LL57 2PW,UK

\section{AGAINST}

Academic psychiatry is not for sale. However, the labours of academic psychiatrists, like those of barristers, stone masons, plumbers or engineers are exchanged for money every day, everywhere.

In the USA, at least, virtually no departmental support is available to underwrite research and, increasingly, external funds are necessary. The pharmaceutical industry has been a relatively consistent source of funding - if the investigator is willing to study a topic of interest to the potential sponsor. This is preferable to indentured servitude. However, industry-funded research is almost universally regarded by academicians as less prestigious or less important - authorship opportunities are limited and papers typically receive lower marks in objectivity or quality (Rochon $e t$ al, 1994, 2002). Consequently, many other scholarly activities will have a higher career pay-off.

Should individual academics be permitted to sell their services to the pharmaceutical industry? Discussion can be guided by established legal, moral and ethical principles. At the most explicit level, if the terms of employment between the academic and his or her employer forbid collaboration with the pharmaceutical industry, the academic must obtain a new contract or employer before initiating such work. If these services are not proscribed, then there is no legal problem.

Academics working with the pharmaceutical industry may be chastised on moral or ethical grounds. The moral high ground rapidly transforms into a slippery slope, however, if value judgements are mistaken for ethical standards. One person may consider that a colleague's collaboration with the pharmaceutical industry reflects greed, but another may judge the critic to be envious or sanctimonious. Is greed inherently worse than envy?

Is it immoral for an academician to work with the pharmaceutical industry? If one accepts immoral behaviour as a violation of accepted or established principles of goodness (i.e. choosing between agreed definitions of right and wrong) then the answer must be 'No!'

Collaborations between universitybased researchers and various industries exist across disciplines. Indeed, more than half of all clinical research is funded by the pharmaceutical industry (Saver et al, 2002). It would be difficult to develop and maintain expertise without, at some point, working with drug companies. In fact, the vast majority of experts selected to develop clinical practice guidelines have some financial relationships with the pharmaceutical industry, typically including some of the medications being evaluated in those guidelines (Choudhry et al, 2002). Is this a shocking revelation? No academics are selected to work on guideline panels precisely because of their expertise, which typically includes experience conducting industry-sponsored clinical research. Is this evidence that we are 'on the take'? No - the pharmaceutical industry is virtually the only source of discovery and development of novel therapeutic compounds.

In this era of government limits on health-care spending, many are understandably critical of the profits made by 'big pharma', but to suggest that it is wrong to work with the industry because it is profitable (Anonymous, 2002) appears to confuse personal opinion with morals. After all, the same industry is permitted to buy advertising space in our journals.

It is not unethical to be paid to consult with, or conduct research funded by drug companies. It could even be argued that it is unethical to deny our expertise to the industry that develops new treatments. If work is performed but the prospect of receiving industry funding is perceived to be too heinous to contemplate, income could always be donated to charities. It could also be considered 'ethical' to provide professional services gratis to a for-profit business (although here the term 'foolish' comes to mind).

Having established that it is not unlawful, immoral or unethical to work with the pharmaceutical industry, there is little doubt that some academics behave unethically, dishonourably or even illegally in these relations. However, there is no evidence that the risk of scientific misconduct in industry-sponsored clinical research is any greater than that in more prestigious, federally funded studies. The potential for industry-related conflicts is endemic. There 
is evidence that even relatively modest 'favours' from the pharmaceutical industry can affect physician behaviour (Campbell et al, 1998; Smith, 1998; Wazana, 2000). It is also true that it is easier to document potential conflicts of interest when money changes hands than when the conflict is ideological or personal (Kjaergard \& AlsNielsen, 2002)

Guidelines are continuously evolving to help academics to behave ethically in their relations with drug companies. At present, the most widely endorsed ethical standard is transparency (i.e. explicit reporting of relationships with the pharmaceutical industry). This is not foolproof, however, and dishonest individuals can simply lie about the nature and extent of their relationships with industry. Honest mistakes can also happen. There is a shadowy boundary between industry-funded promotional activities and those that qualify for continuing medical education credits.

There are a number of grey areas and complexities. For example, can one peerreview a paper reporting research findings if one has received funding from a company that manufactures a rival compound (Mowatt et al, 2002)? What if the funding was from a formerly unrelated company that has now merged? Current standards should not be used to judge activities that may have appeared above-board a decade earlier. In today's 'affectively charged' climate, simply pointing out a relationship with the pharmaceutical industry seems to be sufficient grounds to challenge the results of a study.
I hope that we come to our senses and exercise some collective good judgement before rigid regulations or reactionary policies are developed to try to safeguard our integrity. Even an ideal regulatory system must depend on the integrity of individual investigators (Miller et al, 1998). I humbly suggest that each of us be held accountable for our integrity. I suggest that academics hold the products of their industry-funded efforts to the highest standard of conduct. Towards this end, I encourage journal reviewers to question possible bias whenever it is suspected. If a continuing education talk appears to be too 'lopsided', challenge the speaker and write negative comments. I embrace the reader's right to disagree and respect that academic psychiatrists may value completely different endeavours. I accept that some of this Journal's readers will presume that my work is biased because I have multiple links with the pharmaceutical industry. Please do not, however, continue to confuse your value judgements with my ethics.

Michael E.Thase University of Pittsburgh Medical Center,Western Psychiatric Institute and Clinic, 38II O'Hara Street, Pittsburgh, PA I5213-2593, USA

\section{FURTHER READING}

Anonymous (2002) Just how tainted has medicine become? Lancet, 359, 1167.
Campbell, E. G., Louis, K. S. \& Blumenthal, D. (1998) Looking a gift horse in the mouth. Corporate gifts supporting life sciences research. Journal of the American Medical Association, 279, 995-999.

Carpenter, W. T. (2002) From clinical trial to prescription. Archives of General Psychiatry, 59, 282-285.

Choudhry, N. K., Stelfox, H.T. \& Detsky, A. S. (2002) Relationships between authors of clinical practice guidelines and the pharmaceutical industry. Journal of the American Medical Association, 287, 612-617.

Healy, D. (2002) The Creation of Psychopharmacology. Cambridge, MA: Harvard University Press.

Kjaergard, L. L. \& Als-Nielsen, B. (2002) Association between competing interests and authors' conclusions: epidemiological study of randomised clinical trials published in the BMJ. BMJ, 325, 249-252.

Miller, F. G., Rosenstein, D. L. \& DeRenzo, G. (1998) Professional integrity in clinical research. Journal of the American Medical Association, 280, 1449-1454.

Mowatt, G., Shirran, L., Grimshaw, J. M., et al (2002)

Prevalence of honorary and ghost authorship in Cochrane reviews. Journal of the American Medical Association, 287, 2769-277I.

Rochon, P. A., Gurwitz, J. H., Cheung, C. M., et al (1994) Evaluating the quality of articles published in journal supplements compared with the quality of those published in the parent journal. Journal of the American Medical Association, 272, 108-113.

_, Bero, L. A., Bay, A. M., et al (2002) Comparison of review articles published in peer-reviewed and throwaway journals. Journal of the American Medical Association, 287, 2853-2856.

Saver, J. L., Kidwell, C. S. \& Starkman, S. (2002) Thrombolysis in stroke: it works! BM], 324, 727-729.

Smith, R. (1998) Beyond conflict of interest. BMJ, 317, 291-292.

Torrey, E. F. (2002) The going rate on shrinks. Big pharma and the buying of psychiatry. American Prospect, 15 July, I5-16.

Wazana, A. (2000) Physicians and the pharmaceutical industry: is a gift ever just a gift? Journal of the American Medical Association, 283, 373-380. 